\title{
Laparoscopic Transabdominal Preperitoneal Repair of Spigelian Hernia: Case Report
}

\author{
José Luis Calderón1*, Sandra Danahe Díaz², Luis Miguel Zamora ${ }^{3}$ \\ ${ }^{1}$ General Surgery Department, Hospital Angeles Clínica Londres, Mexico City, Mexico \\ ${ }^{2}$ Anesthesiology Department, Hospital Angeles Clínica Londres, Mexico City, Mexico \\ ${ }^{3}$ General Surgery Resident, Hospital Angeles Lomas, Mexico’s State, Mexico \\ Email: *jefaturaquirofano.londres@saludangeles.com
}

How to cite this paper: Calderon, J.L., Díaz, S.D. and Zamora, L.M. (2021) Laparoscopic Transabdominal Preperitoneal Repair of Spigelian Hernia: Case Report. Surgical Science, 12, 404-410. https://doi.org/10.4236/ss.2021.1212043

Received: November 26, 2021

Accepted: December 25, 2021

Published: December 28, 2021

Copyright () 2021 by author(s) and Scientific Research Publishing Inc. This work is licensed under the Creative Commons Attribution International License (CC BY 4.0).

http://creativecommons.org/licenses/by/4.0/ (c) (i) Open Access

\begin{abstract}
Spigelian Hernia $(\mathrm{SH})$ is an uncommon anterior abdominal wall defect, it represents $0.1 \%-2 \%$ of all abdominal wall hernias. SHs have been traditionally repaired by open technique, but laparoscopic approaches are becoming more common and widely described in the literature. Here we present a case report of a 69-year-old woman who presented with abdominal pain, nausea, abdominal distention and absence of bowel movements for 2 days. A computed tomography performed in an external facility revealed a right-sided and incarcerated SH containing bowel and mesentery. The patient was treated surgically and the abdominal wall defect was repaired by a laparoscopic transabdominal preperitoneal (TAPP) approach. The patient was discharged 24 hours after surgery in excellent conditions. We hold that the TAPP approach is anatomically the soundest repair, with all the added benefits of minimally invasive surgery.
\end{abstract}

\section{Keywords}

Spigelian Hernia, Hernia of the Semilunar Line, Laparoscopic Hernia Repair, Ventral Hernia

\section{Introduction}

Spigelian Hernia (SH), also known as "hernia of the semilunar line" or "spontaneous lateral ventral hernia" represents a rare ventral abdominal wall defect and probably under diagnosed. It has variable incidence, ranging from $0.1 \%$ to $2 \%$ [1], named after Adrian van der Spieghel, a Belgian anatomist of the $17^{\text {th }}$ century, who first described the semilunar line. SH appears when an aponeurotic defect develops between the semilunar line and the lateral margin of the rectus 
abdominis muscle, this was first described by the Flemish anatomist Josef Klinkosh in 1764 [2]. SH is thought to result from fascial weakness related to perforating vessels [3].

SH can be acquired or congenital, slightly more common in women, mostly on the right side and appears to peak between the $4^{\text {th }}$ to $7^{\text {th }}$ decade of life [4] [5]. Diagnosis of SH tends to be difficult as the hernia might be intraparietal, masked by the aponeurosis of the external oblique muscle and abdominal fat, with no obvious mass on inspection or palpation [5]. Symptoms may vary from pain, abdominal mass or features of intestinal obstruction. Sometimes they may be incidentally found in imaging studies or surgery.

Surgical repair of $\mathrm{SH}$ is advisable, as there is a higher risk of incarceration or strangulation in up to $17 \%$ to $25 \%$ of patients [6]. Traditionally, the repair of $\mathrm{SH}$ was made with an open anterior approach with primary suture or mesh placing. The laparoscopic approach was first described by Carter and Mizes in 1992 [7]. Since then, an increasing number of Spigelian hernias are being repaired by this method, because of the advantages that minimally invasive surgery offers, such as reduction of postoperative pain, shorter hospital stay, fewer infections, less morbidity and better cosmesis. The most popular laparoscopic SH repair is the Intraperitoneal Onlay Mesh (IPOM) technique (35\%), followed by the Total Extraperitoneal Patch (TEP) approach (30\%), Transabdominal Preperitoneal Patch (TAPP) approach (22\%), and laparoscopic suturing techniques [5] [8].

Here we present a case report of a TAPP approach for SH repair. The adoption of this technique aids in confirming the correct diagnosis, allows the assessment of the viability of the hernia sac content and has all the benefits of minimally invasive surgery.

\section{Case Presentation}

A 69 -year-old female with body mass index of $36.4 \mathrm{~kg} / \mathrm{m}^{2}$ and medical history significant for inguinal hernia repair and transvaginal hysterectomy with associated anterior colpoperineoplasty, was admitted to our hospital complaining of abdominal pain, discomfort, nausea, abdominal distention and absence of bowel movements in the past 2 days. Physical examination revealed a painful, non-reducible bulky palpable $1.1 " \times 0.7^{\prime \prime}$ mass on the right side of the patient. Laboratory tests were relevant for WBC $11.3 \times 10^{9} / \mathrm{L}$ and LDH $290 \mathrm{UI} / \mathrm{L}$. A computed tomography of the abdomen, performed in an external facility, revealed a right-sided incarcerated 0.9 " SH containing bowel and mesentery.

The patient was taken to the operating room and was positioned on left decubitus. Under general anesthesia, pneumoperitoneum was created using a Veress needle placed at Palmer's point. Two $11-\mathrm{mm}$ and one $5-\mathrm{mm}$ trocars were inserted (Figure 1). A diagnostic laparoscopy was performed, finding an $0.9^{\prime \prime} \mathrm{di}-$ ameter abdominal wall defect in the right side of the abdomen, just below the semilunar line (Figure 2). No content was found in the hernia sac, we believe it reduced spontaneously during abdominal cavity insufflation, appreciating 3 " of 
erythematous small bowel adjacent to the hernia site. The hernia sac was dissected and the margins of the abdominal wall defect were determined (Figure 3). Due to the different muscular layers that $\mathrm{SH}$ comprises, closure of the defect was made using intracorporeal continuous sutures with polypropylene 2-0 (Figure 4(B)). A polypropylene mesh (Prolene ${ }^{\circledR}$ Mesh, PMH, $6 \times 6$ ", Ethicon) was cut to match a size of $4 \times 4$ " (Figure $4(D)$ ), and then was inserted through the 11-mm trocar. The mesh was unfolded, placed in the preperitoneal space and fixed to the posterior abdominal wall with interrupted intracorporeal sutures with polypropylene 2-0. Afterwards, the peritoneal flap was closed with intracorporeal continuous sutures with poliglecaprone 25 2-0 (Figure 5).

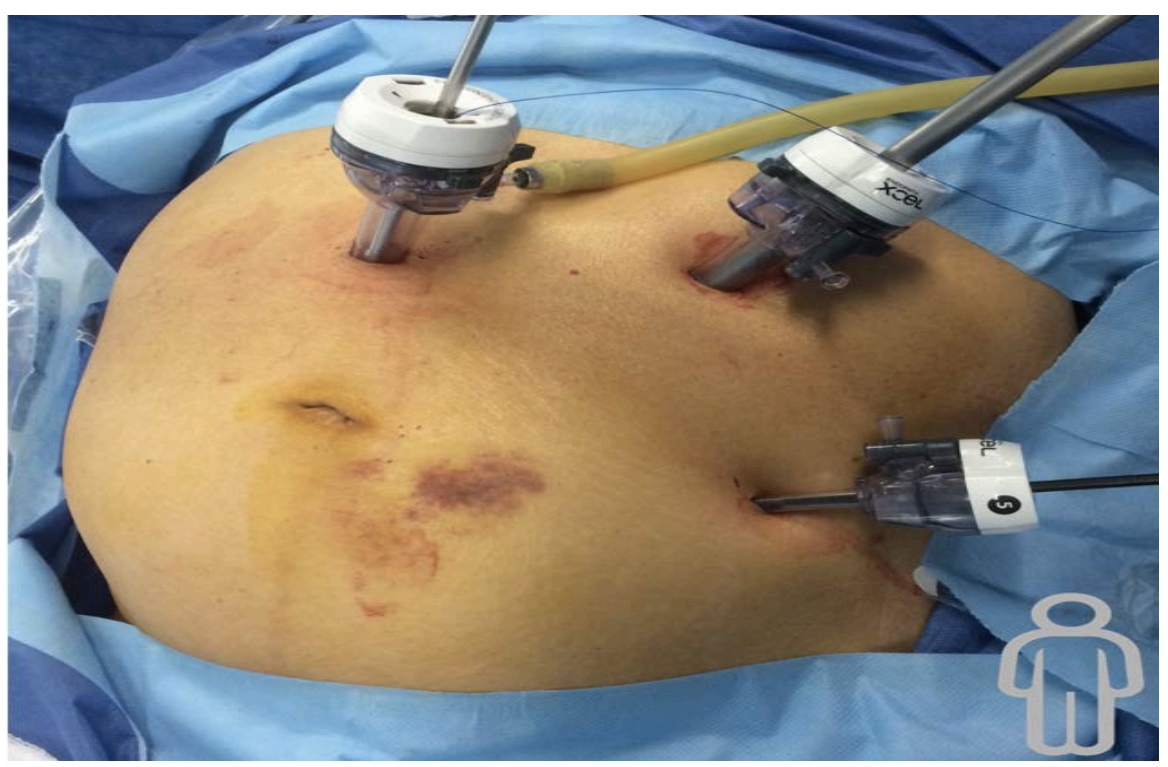

Figure 1. A three-port approach was made, with two 11-mm and one 5-mm trocars. A 3 4" distance between them was estimated and they were, arranged in a crescent shape around the wall defect.

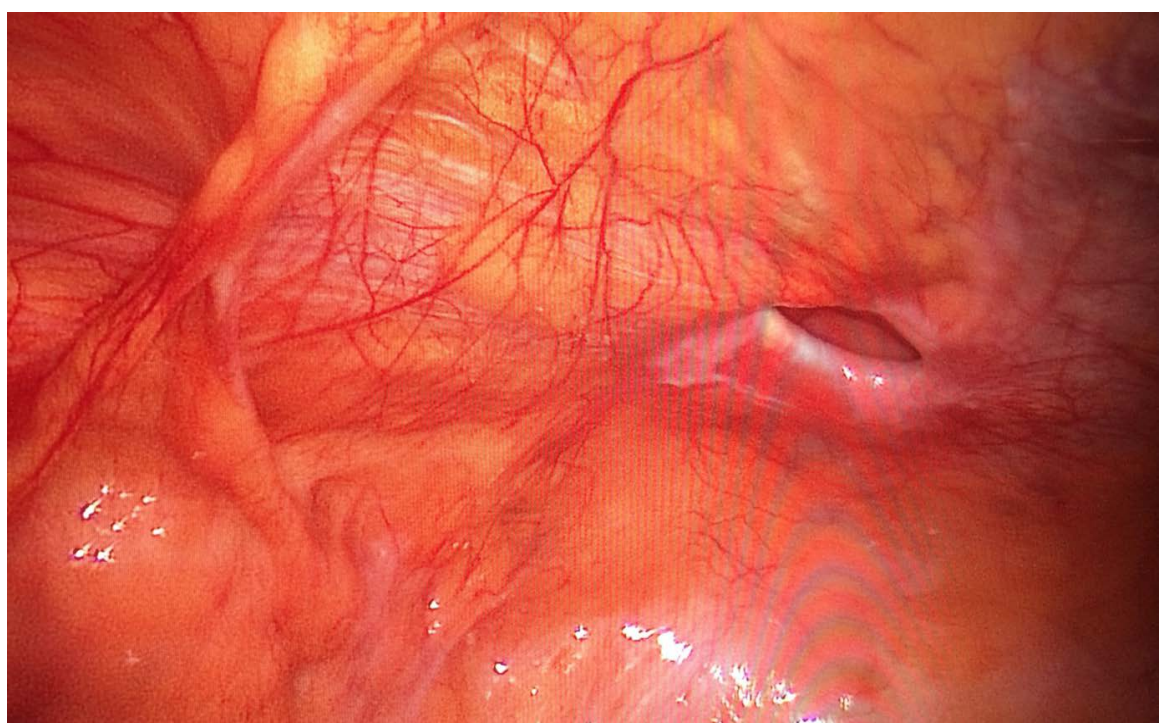

Figure 2. Abdominal wall defect just below the Semilunar line from a laparoscopic view. 
Total operative time was 89 minutes. Postoperative period was uneventful, no seroma or bulging was noted and the patient was discharged in excellent conditions 24 hours after surgery. At follow-up, after 2 months, the patient reported good recovery, no pain, no palpable masses and an excellent cosmetic result.

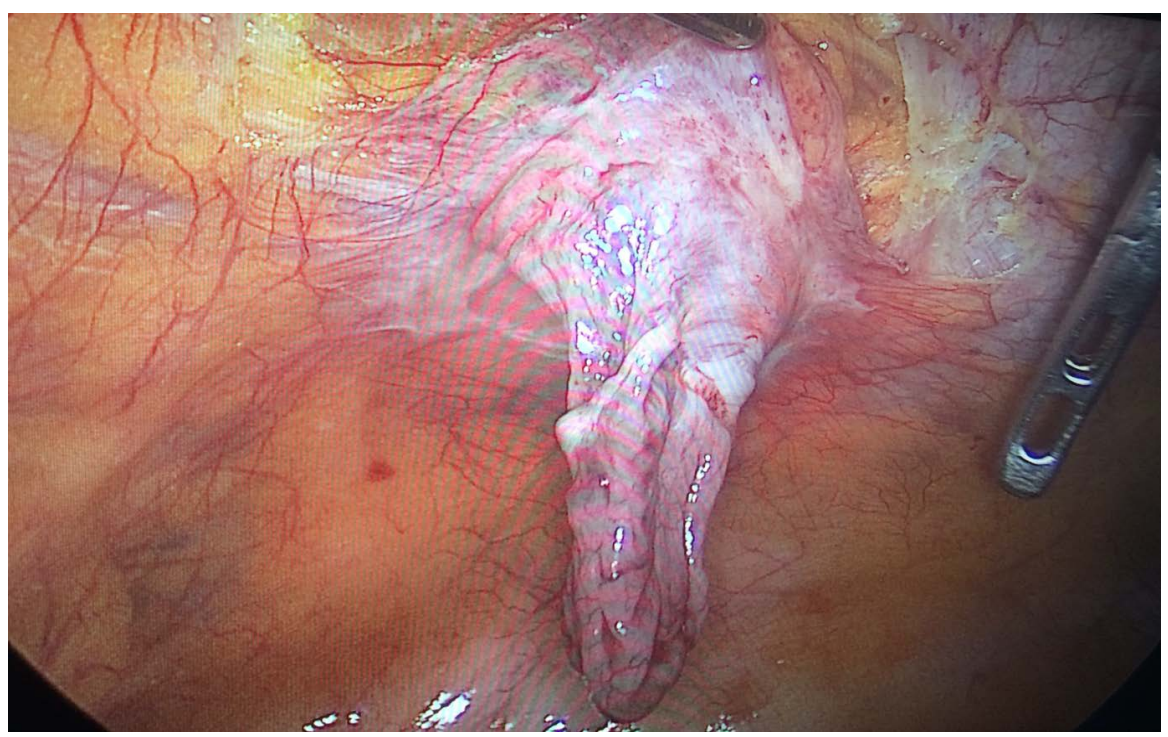

Figure 3. Spiegel Hernia sac dissected into the abdominal cavity.

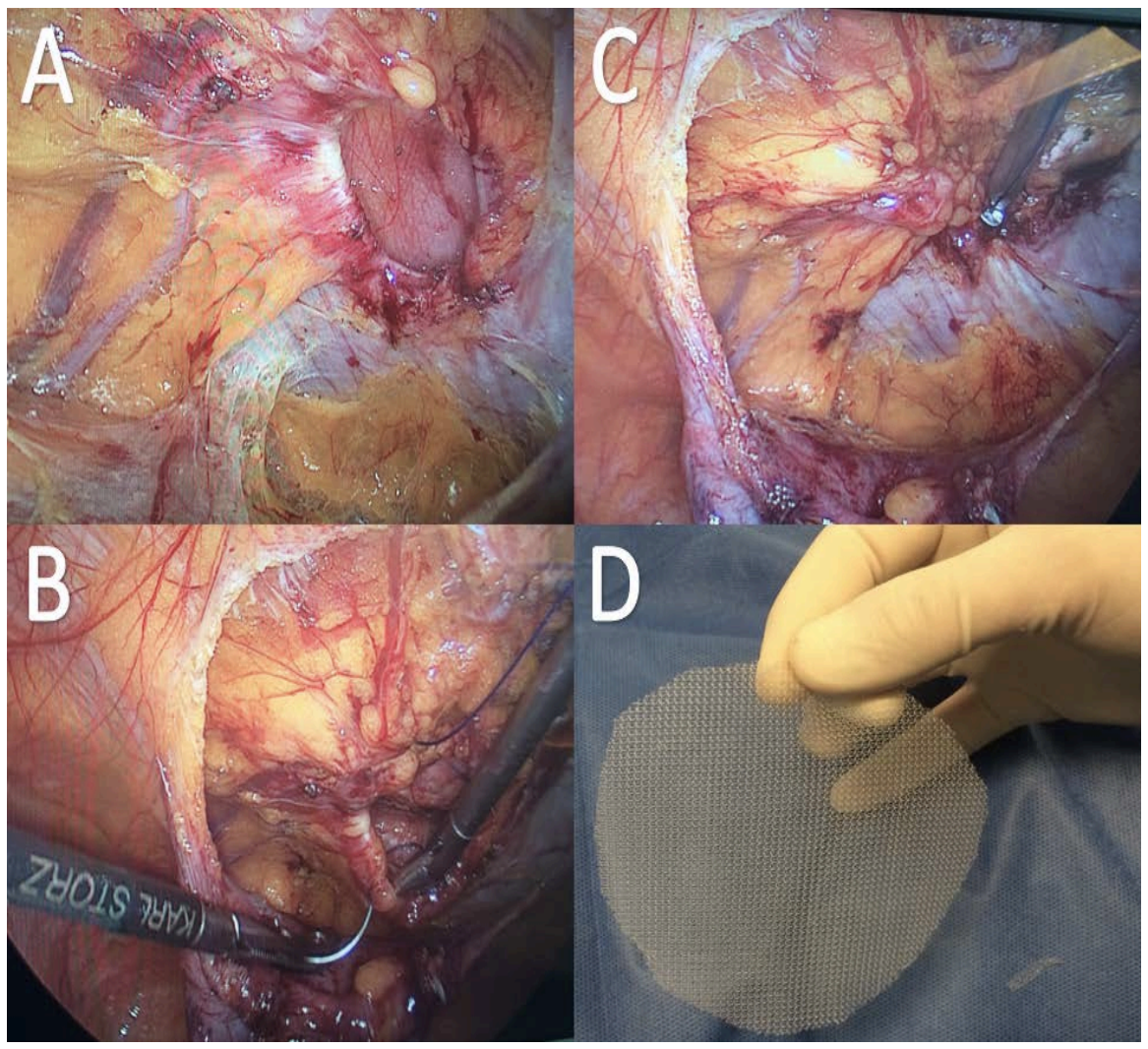

Figure 4. Spigelian hernia defect from a laparoscopic preperitoneal point of view A). Defect being closed laparoscopically with absorbable suture (B-C). Polypropylene mesh concoct for the patient (D). 


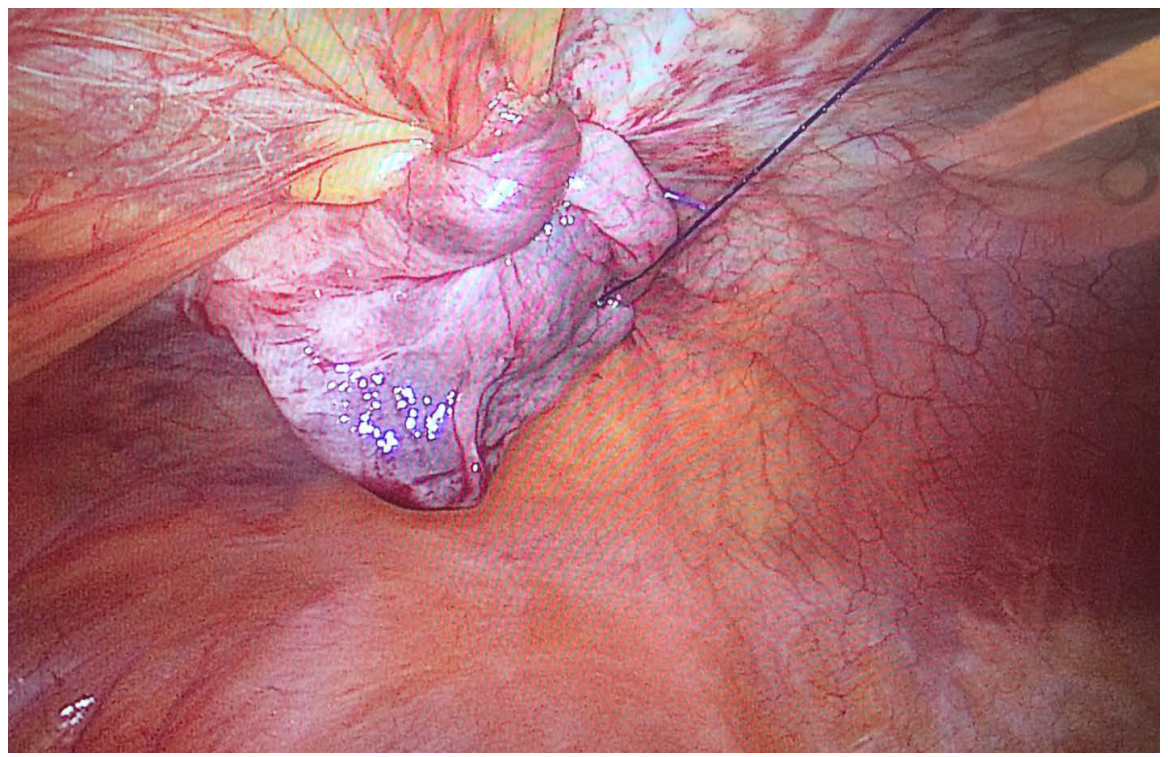

Figure 5. Defect repaired with the hernia sac sutured to the peritoneum.

\section{Discussion}

Spigelian hernias usually appear when there is an aponeurotic defect with boundaries being the semilunar line and the lateral border of the abdominal rectus muscle, through which intraabdominal structures protrude. More than $90 \%$ of the SH are found in the so called "Spigelian belt", a 2.5" wide transverse zone located above the interspinous plane [3]. The hernia defect is covered by the external oblique muscle, which makes it very difficult to detect by palpation [9].

$\mathrm{SH}$ diagnosis requires a high level of suspicion, since in the clinical setting and physical examination usually remains unnoticed [10] [11]. The increase in the use of CT Scan in the evaluation of patients with acute abdomen and/or abdominal tumors probably favors the detection and adequate management in this type of patients [12] [13]. Different techniques for its repair have been described [14]. However, the laparoscopic approach has shown to be superior to open surgery, observing lower morbidity, a shorter hospital stay (1 day vs. 5 days) and a null rate of reported relapses [15].

In the case of our patient, we chose the TAPP approach because of the findings the CT Scan showed, corresponding to a right-sided incarcerated 0.9 " SH containing bowel and mesentery. The TAPP approach allowed us to evaluate the abdominal content and identify the exact location of the abdominal wall defect. Also, anatomically we identified all the essential landmarks for an adequate hernia repair.

The election of the laparoscopic technique depends on the skill of the surgeon, his or her experience, and the basic principles of abdominal wall hernia repair. A three-port management is suggested with a $3-4$ " distance between them, arranged in a crescent shape around the wall defect. The technique may vary depending on the surgical findings as well as the ergonomics of the surgeon.

The TAPP technique is widely used and offers many benefits, such as assess- 
ing the abdominal content and an easier approach due to the ability to identify the exact location of the defect. In addition, it allows other simultaneous procedures to be carried out, in the case that the preoperative diagnosis is mistaken or if there are other intraoperative findings. One possible limitation associated to the TAPP technique, is the potential difficulty of the closure of the peritoneal flap, due to a fragile peritoneum in this location [16]. In that regard, we decided to suture the hernia sac to the peritoneum for closing the peritoneal flap in our patient.

All minimally invasive techniques allow quick recovery, with low pain and a lower postoperative pain.

\section{Conclusion}

Surgeons should always consider the possibility of an SH when evaluating a patient with abdominal pain, intestinal obstruction and an associated mass at the semilunar line. Diagnosis of SH requires a high level of suspicion because the hernia might be intraparietal and masked by the aponeurosis of the external oblique muscle and abdominal fat. CT Scan is suggested for confirming the correct diagnosis; in its absence you can resort to abdominal ultrasound. Regarding treatment, if the necessary resources are available and there is a surgeon with laparoscopic training, we consider that the TAPP approach is the optimal way for repairing these defects, because of the aforementioned advantages.

\section{Conflicts of Interest}

The authors declare no conflicts of interest regarding the publication of this paper.

\section{References}

[1] León, J., Acevedo, A. and Dellepiane, V. (2011) Hernia de Spiegel. Revista Chilena de Cirugía, 63, 64-68. https://doi.org/10.4067/S0718-40262011000100011

[2] Ghosh, S.K., Sharma, S., Biswas, S. and Chakraborty, S. (2014) Adriaan van den Spiegel (1578-1625): Anatomist, Physician, and Botanist. Clinical Anatomy, 2, 952-957. https://doi.org/10.1002/ca.22414

[3] Hanzalova, I., Schäfer, M., Demartines, N., et al. (2021) Spigelian Hernia: Current Approaches to Surgical Treatment-A Review. Hernia. https://doi.org/10.1007/s10029-021-02511-8

[4] Igwe, P.O. and Ibrahim, N.A. (2018) Strangulated Sliding Spigelian Hernia: A Case Report. International Journal of Surgery Case Reports, 53, 475-478. https://doi.org/10.1016/j.ijscr.2018.10.043

[5] Rankin, A., Kostusiak, M. and Sokker, A. (2019) Spigelian Hernia: Case Series and Review of the Literature. Visceral Medicine, 35, 133-136. https://doi.org/10.1159/000494280

[6] Nagarsheth, K.H., Nickloes, T., Mancini, G. and Solla, J.A. (2011) Laparoscopic Repair of Incidentally Found Spigelian Hernia. Journal of Second Language Studies, 15, 81-85. https://doi.org/10.4293/108680811X13022985131372

[7] Carter, J.E. and Mizes, C. (1992) Laparoscopic Diagnosis and Repair of Spigelian 
Hernia: Report of a Case and Technique. The American Journal of Obstetrics and Gynecology, 167, 77-78. https://doi.org/10.1016/S0002-9378(11)91630-5

[8] Webber, V., Low, C., Skipworth, R.J.E., Kumar, S., de Beaux, A. and Tulloh, B. (2017) Contemporary Thoughts on the Management of Spigelian Hernia. Hernia, 21, 355-361. https://doi.org/10.1007/s10029-017-1579-x

[9] Paajanen, H., Ojala, S. and Virkkunen, A. (2006) Incidence of Occult Inguinal and Spigelian Hernias During Laparoscopy of Other Reasons. Surgery, 140, 9-12. https://doi.org/10.1016/j.surg.2006.01.005

[10] Slaiki, S., Hamdane, A., El-Bouhaddouti, H., Ousadden, A., et al. (2020) Spigelian Hernia Case Report and Review of the Literature. International Surgery Journal, 7, 880-882. https://doi.org/10.18203/2349-2902.isj20200839

[11] Fernández-Moreno, M.C., Martí-Cuñat, E., Pou, G. and Ortega, J. (2018) Intraperitoneal Onlay Mesh Technique for Spigelian Hernia in an Outpatient and Short-Stay Surgery Unit: What's New in Intraperitoneal Meshes? Journal of Laparoendoscopic \& Advanced Surgical Techniques, 28, 700-704. https://doi.org/10.1089/lap.2017.0319

[12] Larson, D.W. and Farley, D.R. (2002) Spigelian Hernias: Repair and Outcome for 81 Patients. World Journal of Surgery, 26, 1277-1281. https://doi.org/10.1007/s00268-002-6605-0

[13] Light, D., Chattopadhyay, D. and Bawa, S. (2013) Radiological and Clinical Examination in the Diagnosis of Spigelian Hernias. Annals of the Royal College of Surgeons of England, 95, 98-100. https://doi.org/10.1308/003588413X13511609957092

[14] Bittner, R., Bain, K., Bansal, V.K., Berrevoet, F., et al. (2019) Update of Guidelines for Laparoscopic Treatment of Ventral and Incisional Abdominal Wall Hernias. Surgical Endoscopy, 33, 3069-3139. https://doi.org/10.1007/s00464-019-06907-7

[15] Majeski, J. (2009) Open and Laparoscopic Repair of Spigelian Hernia. International Surgery, 94, 365-369.

[16] Moreno-Egea, A., Campillo-Soto, A. and Morales-Cuenca, G. (2015) Which Should Be the Gold Standard Laparoscopic Technique for Handling Spigelian Hernias? Surgical Endoscopy, 29, 856-861. https://doi.org/10.1007/s00464-014-3738-9

[17] Palanivelu, C., Vijaykumar, M., Jani, K.V., Rajan, P.S., Maheshkumaar, G.S. and Rajapandian, S. (2006) Laparoscopic Transabdominal Preperitoneal Repair of Spigelian Hernia. Journal of Second Language Studies, 10, 193-198. 